\title{
An Analysis and Research on the Transmission Ratio of Dye Sensitized Solar Cell Photoelectrodes by Using Different Etching Process
}

\author{
Chin-Guo Kuo, ${ }^{1}$ Cheng-Fu Yang, ${ }^{2}$ Mu-Jung Kao, ${ }^{3}$ Wen-Pin Weng, ${ }^{4}$ Chi-Cheng Chang, \\ Lih-Ren Hwang, ${ }^{6}$ and Jian-Lan Nil $^{7}$ \\ ${ }^{1}$ Department of Industrial Education, National Taiwan Normal University, Taipei 10610, Taiwan \\ ${ }^{2}$ Department of Chemical and Materials Engineering, National University of Kaohsiung, Kaohsiung 81148, Taiwan \\ ${ }^{3}$ Department of Vehicle Engineering, National Taipei University of Technology, Taipei 10608, Taiwan \\ ${ }^{4}$ Department of Chemical and Materials Engineering, Lunghwa University of Science and Technology, Taoyuan 33306, Taiwan \\ ${ }^{5}$ Department of Information Management, Lunghwa University of Science and Technology, Taoyuan 33306, Taiwan \\ ${ }^{6}$ Department of Automation and Control Engineering, Chung Chou University of Science and Technology, Yuanlin 51003, Taiwan \\ ${ }^{7}$ Department of Mechatronic Technology, National Taiwan Normal University, Taipei 10610, Taiwan
}

Correspondence should be addressed to Mu-Jung Kao; mjkao@ntut.edu.tw

Received 13 December 2012; Revised 5 February 2013; Accepted 22 February 2013

Academic Editor: Ho Chang

Copyright (C) 2013 Chin-Guo Kuo et al. This is an open access article distributed under the Creative Commons Attribution License, which permits unrestricted use, distribution, and reproduction in any medium, provided the original work is properly cited.

Classical photoelectrodes for Dye Sensitized Solar Cells (DSSCs) were fabricated by using the electrochemical method on the titanium (Ti) template, for that the fabrication process would influence the characteristics of the DSSCs. In this study, at first three different methods were used to etch Ti templates from 10 to $17 \mathrm{~min}$, (1) polishing-chemical etching: Ti template was annealed at $450^{\circ} \mathrm{C}$ for $1 \mathrm{~h}$, abraded using number 80 to $1500 \mathrm{SiC}$ sheet, and then etched in a solution of $5 \% \mathrm{HF}+95 \% \mathrm{H}_{2} \mathrm{O}$; (2) electrochemical polishing-chemical etching: Ti template was annealed at $450^{\circ} \mathrm{C}$ for $1 \mathrm{~h}$, electrolytic polishing with $42 \% \mathrm{CH}_{3} \mathrm{OH}+5 \% \mathrm{HClO}{ }_{4}+53 \%$ $\mathrm{HOCH}_{2} \mathrm{CH}_{2} \mathrm{OC}_{4} \mathrm{H}_{9}$ solution, and the chemical-etching in a solution of $5 \% \mathrm{HF}+95 \% \mathrm{H}_{2} \mathrm{O}$; (3) chemical etching: Ti template was etched in a solution of $5 \% \mathrm{HF}+95 \% \mathrm{H}_{2} \mathrm{O}$ and annealed at $450^{\circ} \mathrm{C}$ for $1 \mathrm{~h}$. When the etching time was changed from 10 to $17 \mathrm{~min}$, the thicknesses of Ti templates decreased from $75.3 \mu \mathrm{m}$ to $14.8 \mu \mathrm{m}$, depending on the etching method. After etching process, the $\mathrm{TiO}_{2}$ nanotube arrays were fabricated as the photoelectrode of DSSCs by electrochemical process, in which the Ti as anode and platinum $(\mathrm{Pt})$ as cathode. The electrolyte solution included $\mathrm{C}_{2} \mathrm{H}_{4}(\mathrm{OH})_{2}, \mathrm{NH}_{4} \mathrm{~F}$, and deionized water. After annealing the grown $\mathrm{TiO}_{2}$ nanotube arrays at $450^{\circ} \mathrm{C}$ for $3 \mathrm{~h}$, we would show that the etching process had large effect on the structure and transmittance ratio of the $\mathrm{TiO}_{2}$ nanotube arrays.

\section{Introduction}

Tubular inorganic nanostructures offer great potential for use in heterojunction solar cells, fuel cells, molecular filtration, tissue engineering, and Dye Sensitized Solar Cells (DSSCs). In contrast to random nanoparticle systems where slow electron diffusion typically limits device performance $[1,2]$, the precisely oriented nature of the crystalline (after annealing) nanotube arrays makes them excellent electron percolation pathways for vectorial charge transfer between interfaces $[2,3]$. Highly ordered vertically oriented nanotube arrays fabricated by different metal-oxide can be used as photoelectrode materials of the DSSCs, which include titanium dioxide $\left(\mathrm{TiO}_{2}\right)$ [4], ferric oxide $\left(\mathrm{Fe}_{2} \mathrm{O}_{3}\right)$ [5], zinc oxide $(\mathrm{ZnO})$ [6], and so forth. Among those proposed photoelectrode materials, $\mathrm{TiO}_{2}$ is best because it has the merits of low cost, chemical stability, and good charge transport [7].

As numerous major advances in research and technology over the past decade have been made possible by the successful development of nanostructures, various avenues have been used to fabricate a diversity of $\mathrm{TiO}_{2}$ nanostructure photoelectrodes, including the sol-gel method [8], metalorganic 


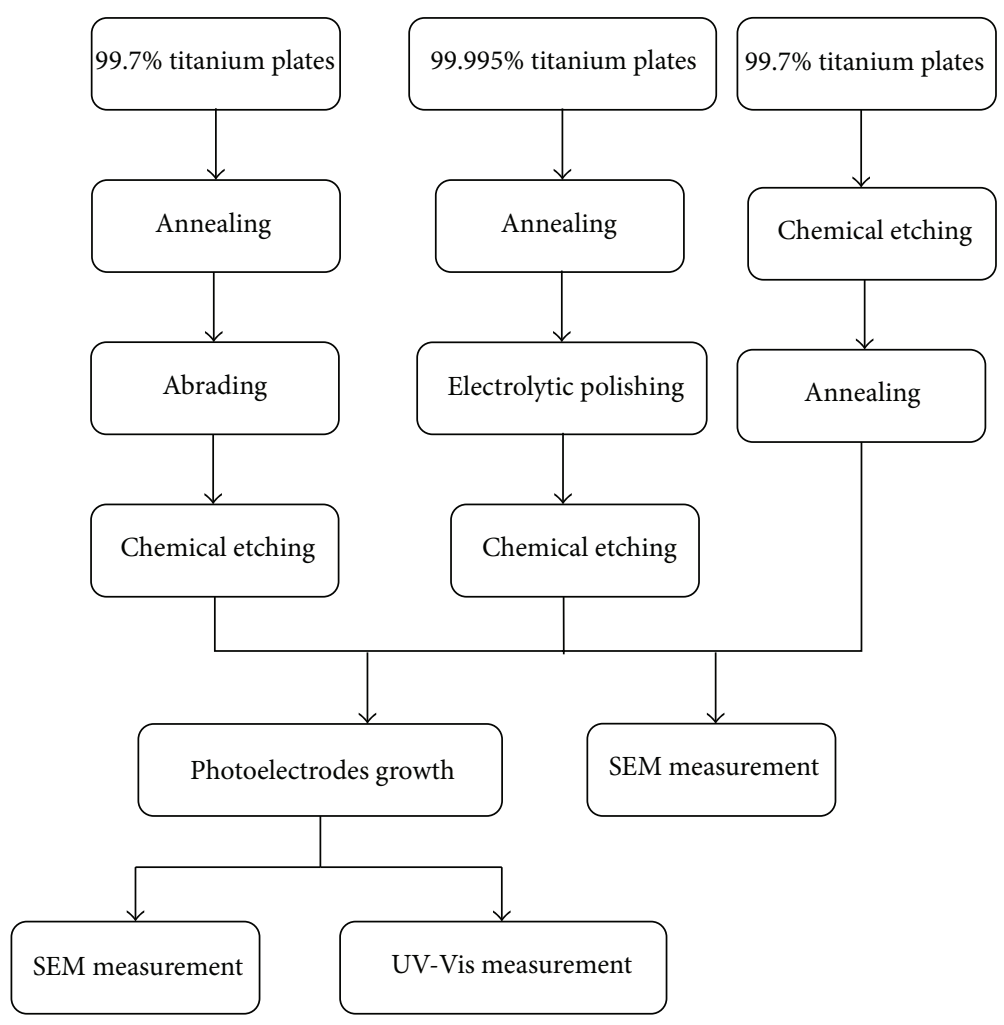

FIGURE 1: Experimental flow chart.

chemical vapor deposition (MOCVD) [9], templating [10], and electrochemical method [11]. Although many of those fabrication routes are complicated due to the use of templates or the nature of the involved chemical processes, it has been demonstrated that self-organized vertically oriented titanium dioxide $\left(\mathrm{TiO}_{2}\right)$ nanotube arrays can be fabricated using a simple anodization technique. Using electrochemical method to fabricate the $\mathrm{TiO}_{2}$ nanotube arrays as photoelectrodes is first one using hydrofluoric acid (HF) electrolyte by Zwilling et al. [12]. After that, many electrolytes are also developed to fabricate the $\mathrm{TiO}_{2}$ nanotube arrays as photoelectrodes, such as $\mathrm{HF} / \mathrm{H}_{2} \mathrm{O}, \mathrm{HF} / \mathrm{H}_{2} \mathrm{SO}_{4} / \mathrm{H}_{2} \mathrm{O}$ [13], and EG (ethylene glycol) $/ \mathrm{NH}_{4} \mathrm{~F} / \mathrm{H}_{2} \mathrm{O}$ [14]. When the $\mathrm{EG} / \mathrm{NH}_{4} \mathrm{~F} / \mathrm{H}_{2} \mathrm{O}$ electrolyte is used to fabricate $\mathrm{TiO}_{2}$ nanotube arrays, the length of $\mathrm{TiO}_{2}$ photoelectrodes has the value between $10 \mu \mathrm{m}$ and $100 \mu \mathrm{m}[14]$.

When using as the photoelectrodes, the property of the anatase phase $\mathrm{TiO}_{2}$ is believed to be superior than that of the rutile phase $\mathrm{TiO}_{2}$. Because the band gap of anatase phase $\mathrm{TiO}_{2}$ is $3.2 \mathrm{eV}$ and rutile phase $\mathrm{TiO}_{2}$ is $3.0 \mathrm{eV}$, the light absorption edge of anatase phase $\mathrm{TiO}_{2}$ is located at lower wavelength. When the ultraviolet light is irradiated, the photoelectrodes of $\mathrm{TiO}_{2}$ nanotube arrays are proceeded photocatalytic activities to make light through photoelectrodes to dye layer [15]. Except the crystalline phase, when the $\mathrm{TiO}_{2}$ nanotube arrays are used as the photoelectrodes, the transmission ratio of $\mathrm{TiO}_{2}$ nanotube arrays has large effect on the efficiency of the fabricated DSSCs. In this study, Dye Sensitized Solar Cells (DSSCs) photoelectrodes, $\mathrm{TiO}_{2}$ nanotube arrays, were fabricated by using electrochemical

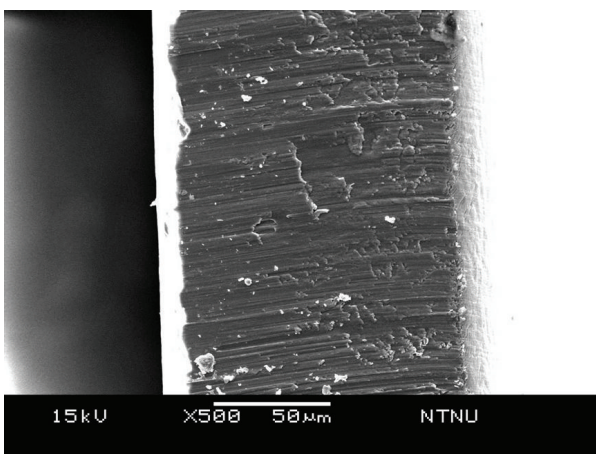

FIGURE 2: Cross-section observation of annealed titanium plate.

method and using UV-Vis examination transmission ratio in the DSSCs structure. Therefore, the purpose of this study was to investigate the effect of etching process on transmission ratio of the $\mathrm{TiO}_{2}$ nanotube arrays after treating by using different etching methods.

\section{Experimental}

The Ti metals were cut into Ti-plates with a size of $2.5 \mathrm{~cm}$ $\times 2.5 \mathrm{~cm}$ and thickness of $\sim 142 \mu \mathrm{m}$. The flow chart for the different etching process, the process for formation of $\mathrm{TiO}_{2}$ nanotube arrays, and the characteristic measurements of the $\mathrm{TiO}_{2}$ nanotube arrays was shown in Figure 1 and described below. 


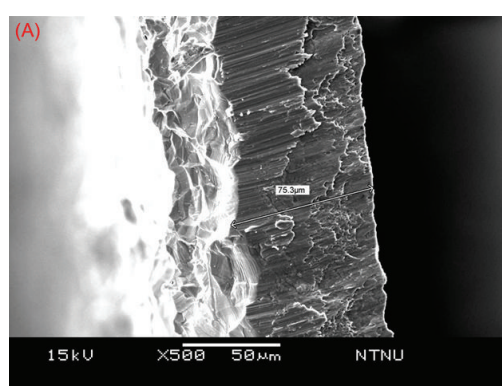

(a)

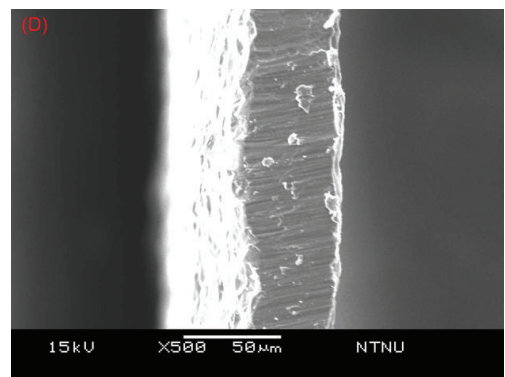

(d)

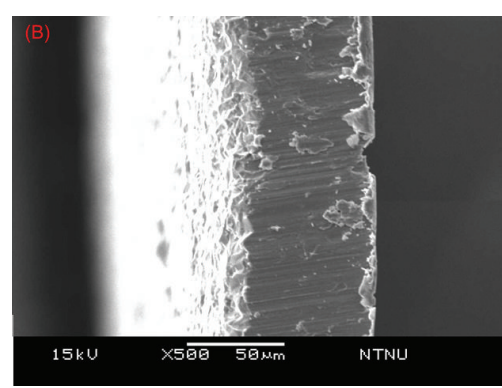

(b)

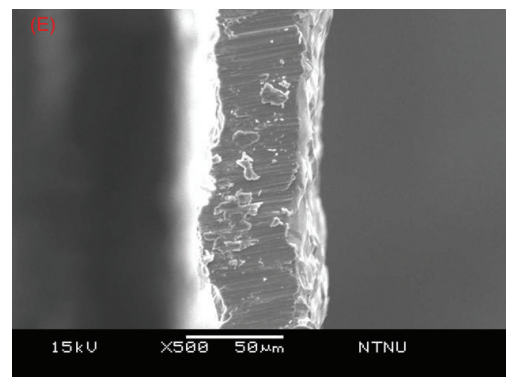

(e)

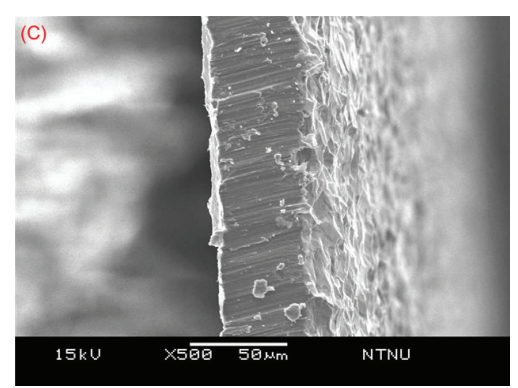

(c)

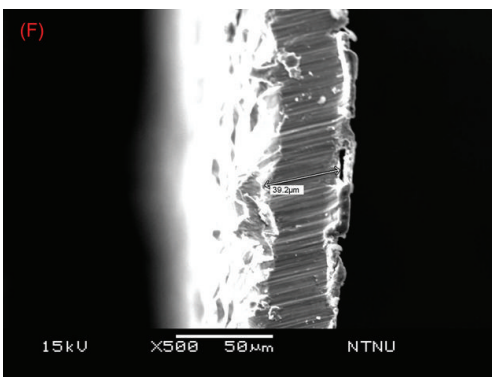

(f)

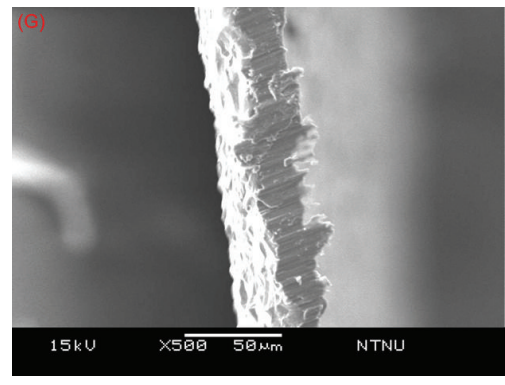

(g)

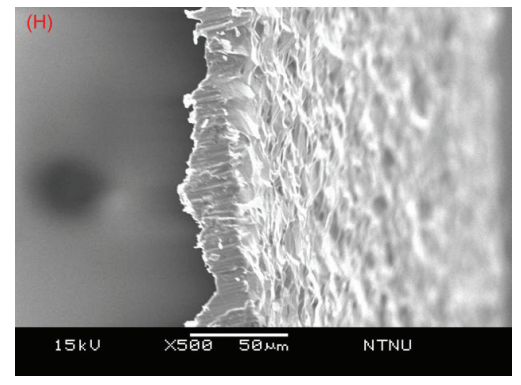

(h)

FIGURE 3: Cross-section morphologies of polishing-chemical etching under different times (a) $10 \mathrm{~min}$, (b) $11 \mathrm{~min}$, (c) $12 \mathrm{~min}$, (d) $13 \mathrm{~min}$, (e) $14 \mathrm{~min}$, (f) $15 \mathrm{~min}$, (g) $16 \mathrm{~min}$, and (h) $17 \mathrm{~min}$.

\subsection{Preprocess}

2.1.1. Polishing-Chemical Etching. A pure Ti plate with $99.7 \%$ purity was used as the template for the polishing-chemical etching process. The template was first annealed $1 \mathrm{~h}$ at $450^{\circ} \mathrm{C}$ and cooled in air, then the template was abraded using $\mathrm{SiC}$ sheets (Nos 80 to 1500), and then it was ultrasonicated for $30 \mathrm{~min}$ in distilled water. After that, the mixture of $5 \% \mathrm{HF}+$ $95 \% \mathrm{H}_{2} \mathrm{O}$ was used as the etching solution and the etching time was changed from 10 to $17 \mathrm{~min}$.

2.1.2. Electrochemical Polishing-Chemical Etching. Another titanium plate with higher purity $99.995 \%$ was also used as the template, too. The sample was first annealed $1 \mathrm{~h}$ at $450^{\circ} \mathrm{C}$ and then it was ultrasonicated for $30 \mathrm{~min}$ in distilled water. The polishing electrolytic solution was mixed with $42 \%$ methanol $\left(\mathrm{CH}_{3} \mathrm{OH}\right)+5 \%$ perchloric acid $\left(\mathrm{HClO}_{4}\right)+53 \%$ ethylene glycol monobutylether $\left(\mathrm{HOCH}_{2} \mathrm{CH}_{2} \mathrm{OC}_{4} \mathrm{H}_{9}\right)$, and the etching solution was mixed by $5 \% \mathrm{HF}+95 \% \mathrm{H}_{2} \mathrm{O}$; the etching time was changed from 10 to $17 \mathrm{~min}$.
2.1.3. Chemical Etching. A pure titanium plate with $99.7 \%$ purity was also used as the template for the chemical etching process. The mixture of $5 \% \mathrm{HF}+95 \% \mathrm{H}_{2} \mathrm{O}$ was used as the etching solution and the etching time was changed from 10 to 16 minutes. After the etching process the titanium plate was annealed at $450^{\circ} \mathrm{C}$ for $1 \mathrm{~h}$.

2.2. Preparation of Photoelectrodes. We fabricated ordered nanochannel TNT arrays at $25^{\circ} \mathrm{C}$ on the prepared titanium (Ti) square foils $(2 \mathrm{~cm} \times 2 \mathrm{~cm})$ at a constant voltage of $50 \mathrm{~V}$ and $\mathrm{Ti}$ foils as an anode. The electrolyte solutions contained $0.2 \mathrm{M}$ ammonium fluoride $\left(\mathrm{NH}_{4} \mathrm{~F}\right)+2 \% \mathrm{H}_{2} \mathrm{O}$ + ethylene glycol $\left(\mathrm{C}_{2} \mathrm{H}_{4}(\mathrm{OH})_{2}\right)$ with anodization. Ti foils were degreased by ultrasonication in acetone and then isopropanol, respectively, for about $30 \mathrm{~min}$, followed by rinsing with deionized (DI) water, and finally dried in the air before used. Highly ordered $\mathrm{TiO}_{2}$ nanotube arrays over large area were prepared by a potentiostatic anodization in a twoelectrode electrochemical cell with a platinum $(\mathrm{Pt})$ sheet as counter electrode. All anodization experiments were carried 


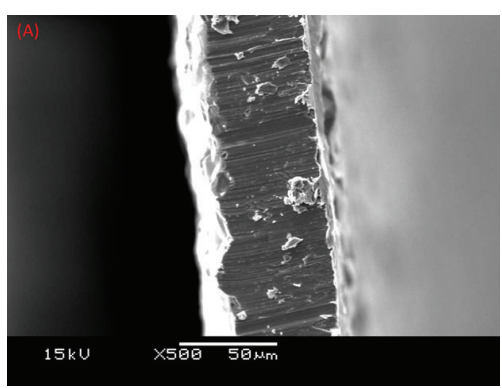

(a)

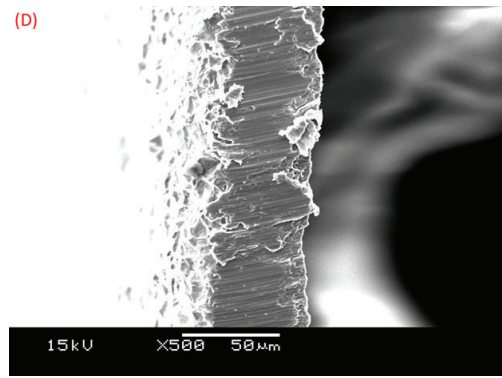

(d)

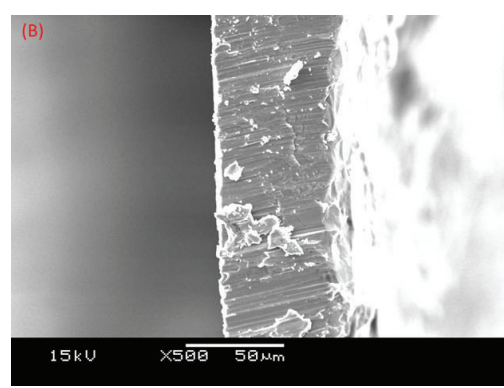

(b)

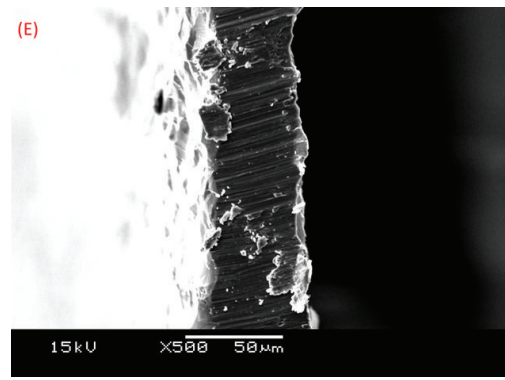

(e)

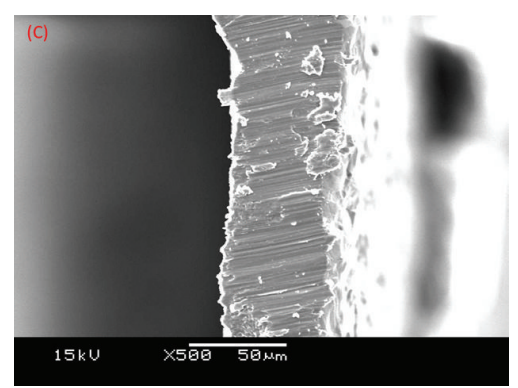

(c)

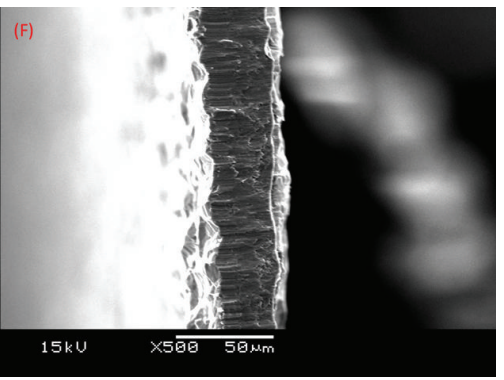

(f)

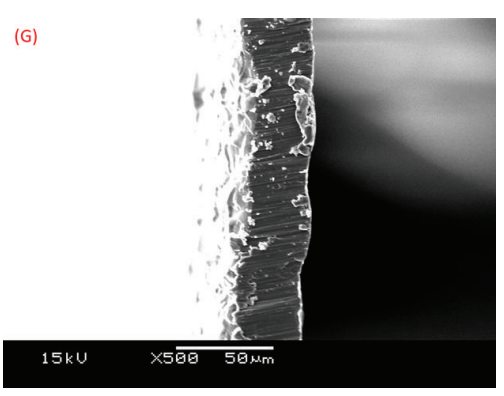

(g)

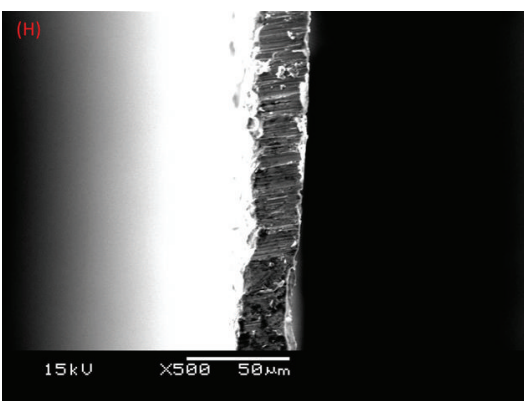

(h)

Figure 4: Cross-section morphologies of electrochemical polishing-chemical etching under different times (a) $10 \mathrm{~min}$, (b) $11 \mathrm{~min}$, (c) $12 \mathrm{~min}$, (d) $13 \mathrm{~min}$, (e) $14 \mathrm{~min}$, (f) $15 \mathrm{~min}$, (g) $16 \mathrm{~min}$, and (h) $17 \mathrm{~min}$.

out at room temperature. After the electrochemical process, the foils were annealed at $450^{\circ} \mathrm{C}$ for $3 \mathrm{~h}$.

\section{Results and Discussion}

3.1. Morphologies for the Cross-Section of Nonetched and Etched Ti Specimens. Figure 2 shows the cross-section of the nonetched and annealed Ti specimen, the nonetched Ti specimen showed a densified structure and no defect and porous were observed. After different etching processes were used, the etch-treated $\mathrm{Ti}$ plates were thoroughly rinsed with distilled water for clean at room temperature and morphologies for the cross-section were observed. In Figures 3-5, a series of micrographs of titanium plate after various etching processes and at different etching time, from 10 to $17 \mathrm{~min}$, are observed. From Figures 2 and 5 , the thickness of titanium plates linearly decreased with etching time and, however, the nonuniformity in thickness became apparently at a longer etching time. For the polishing-chemical etching specimens, as the etching time was equal to and longer $13 \mathrm{~min}$, the thickness become obviously asymmetrical. As shown in Figure 3, the polished surface of Ti plate was changed to be a porous structure after alkali treatment. Apparently, the porosity of the structure was observed to be increased after chemical etching treatment.

For the electrochemical polishing-chemical etching specimens, as Figure 4 shows, asymmetrical in the thickness was not observed even the etching time was $17 \mathrm{~min}$. Figure 4 also shows that even with the electrolytic publishing and chemical etching the Ti plate had a smooth surface. For the results shown in Figure 5, after annealing treatment, the porous structure seemed to become more compact and rigid than before the annealing treatment, and asymmetrical in the thickness was not observed even the etching time was $17 \mathrm{~min}$. A cross-section of the etched Ti plates was observed by using scanning electron microscope (SEM) and the thickness of the Ti plates was measured by SEM. The variation in the thickness of Ti plates under different etching processes as a function of etching time is displayed in Figure 6.

When the etching time was increased from 10 to $17 \mathrm{~min}$, the thicknesses of the polishing-chemical etching, electrochemical polishing-chemical etching, and chemical etching Ti plates decreased from $75.3 \mu \mathrm{m}$ to $33 \mu \mathrm{m}$, from $60.4 \mu \mathrm{m}$ 


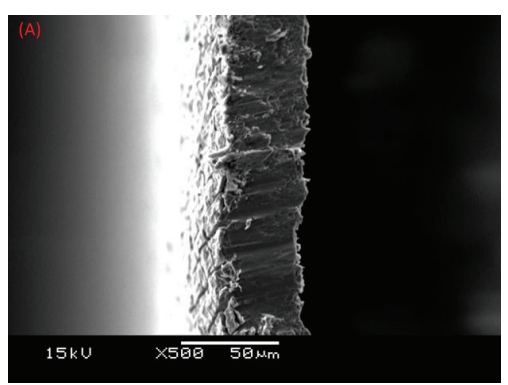

(a)

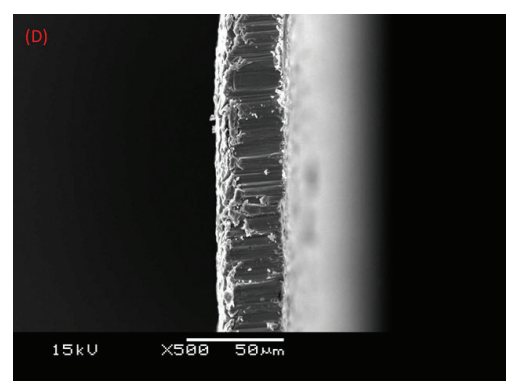

(d)

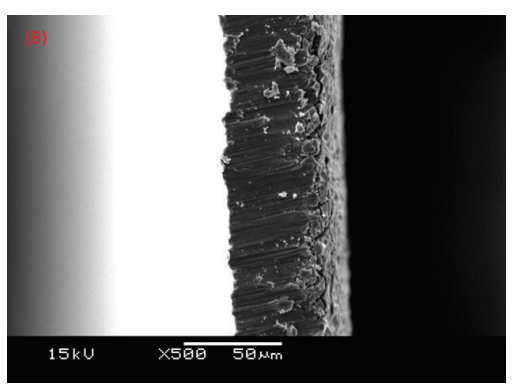

(b)

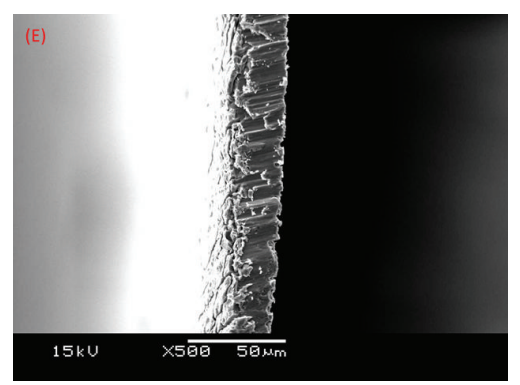

(e)

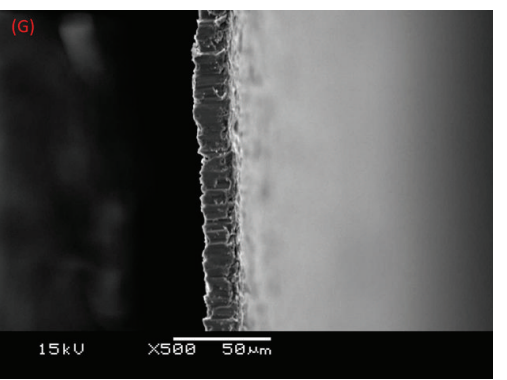

(g)

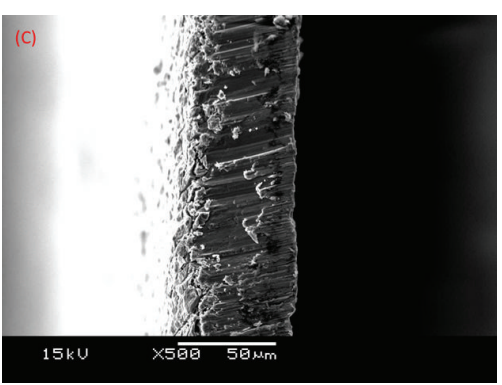

(c)

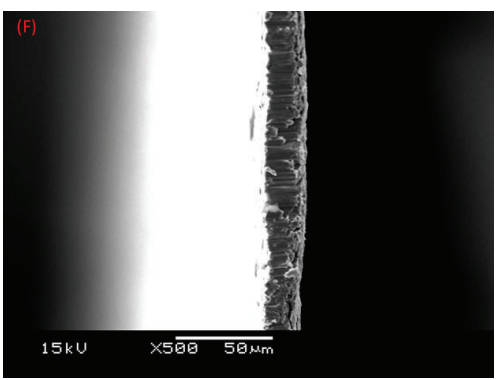

(f)

Figure 5: Cross-section morphologies of chemical etching under different times (a) $10 \mathrm{~min}$, (b) $11 \mathrm{~min}$, (c) $12 \mathrm{~min}$, (d) $13 \mathrm{~min}$, (e) $14 \mathrm{~min}$, (f) $15 \mathrm{~min}$, and (g) $16 \mathrm{~min}$.

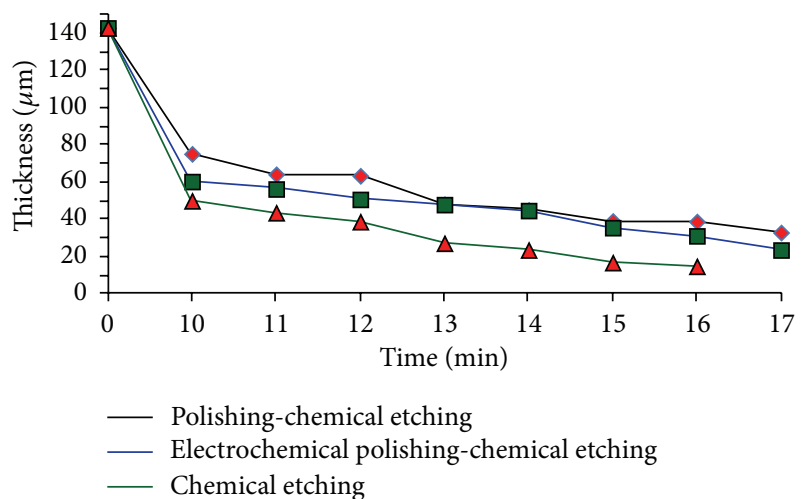

FIGURE 6: Titanium plates thickness curve chart of different methods and etching times.

to $23.6 \mu \mathrm{m}$, and from $50 \mu \mathrm{m}$ to $14.8 \mu \mathrm{m}$, respectively. As Figure 6 shows, as the same etching time is used, the thicknesses of the chemical-etching Ti plates are thinner than those of the other two processes-treated $\mathrm{Ti}$ plates, and the abrading process is the reason to cause this result. From the results shown in Figures 3-5, the porous structure on the surfaces of Ti plates only existed in polishing-chemical etching $\mathrm{Ti}$ plates but not existing in electrochemical polishing-chemical etching and chemical etching $\mathrm{Ti}$ plates. A similar porous structure was reported to be produced by the alkali $(\mathrm{KOH})$ treatment of a commercial $\mathrm{Ti}$ plate; the porous structure was composed of nanowires with a diameter of less than $30 \mathrm{~nm}$, and the thickness of nanowire layer was estimated to be approximately $500 \mathrm{~nm}$ on the Ti substrate [16]. For that, the different etching processes would have large effect on the formation of the $\mathrm{TiO}_{2}$ nanotube arrays. If the thickness of $\mathrm{Ti}$ plates is too thin, the photoelectrodes of the $\mathrm{TiO}_{2}$ nanotube arrays are not easy to be grown; therefore, the 11 min treated Ti plates are chosen for producing the $\mathrm{TiO}_{2}$ nanotube arrays.

3.2. Morphology of $\mathrm{TiO}_{2}$ Nanotube Arrays. From the X-ray diffraction patterns (not shown here), the main crystalline phase of the as-prepared $\mathrm{TiO}_{2}$ nanotube arrays was amorphous, the diffraction peaks of $\mathrm{Ti}$ and rutile $\mathrm{TiO}_{2}$ phases 


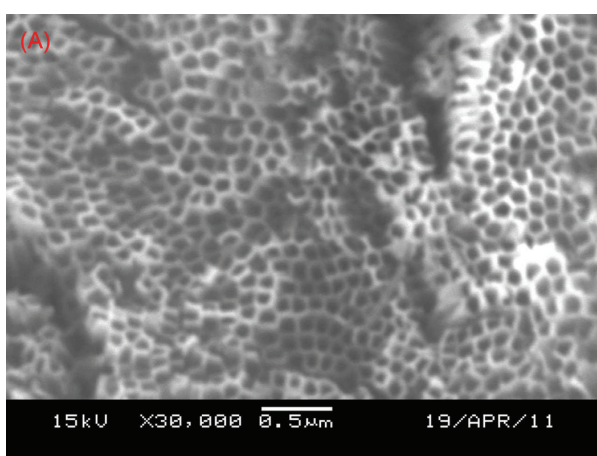

(a)

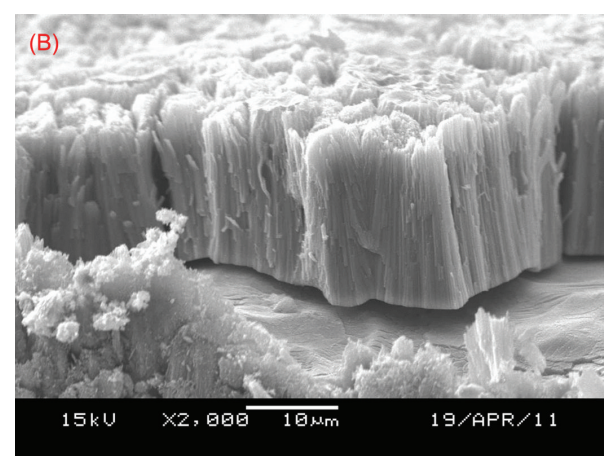

(b)

FIgURE 7: Morphologies of the $\mathrm{TiO}_{2}$ nanotube arrays grown on polishing-chemical etching Ti plate (a) top view and (b) side view.

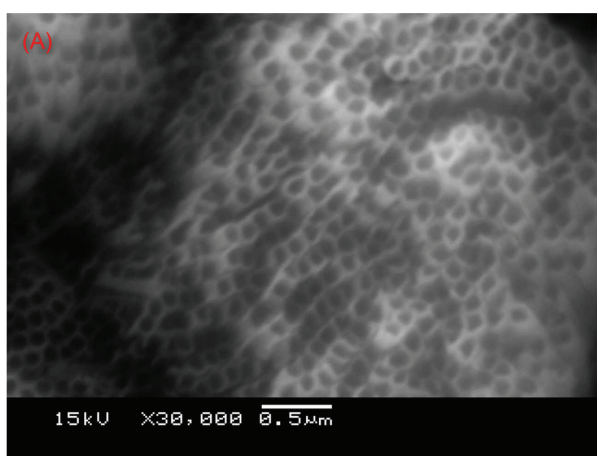

(a)

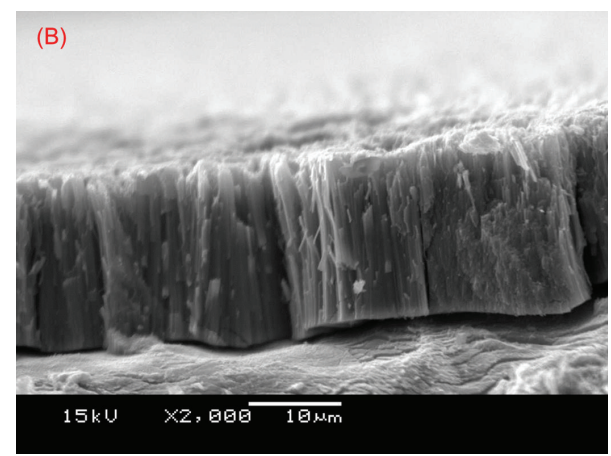

(b)

Figure 8: Morphologies of the $\mathrm{TiO}_{2}$ nanotube arrays grown on electrochemical polishing-chemical etching Ti plates (a) top view and (b) side view.

could be found, and these diffraction peaks were not enhanced as the $\mathrm{TiO}_{2}$ nanotube array length was changed. It is noted that the anatase $\mathrm{TiO}_{2}$ peaks are much worse than the $\mathrm{Ti}$ and rutile $\mathrm{TiO}_{2}$ peaks, so it is reasonable to neglect the influences of such trace anatase $\mathrm{TiO}_{2}$ content in the asprepared $\mathrm{TiO}_{2}$ nanotube arrays. As $\mathrm{TiO}_{2}$ nanotube arrays were annealed at $450^{\circ} \mathrm{C}$ for $1 \mathrm{~h}$, the diffraction peaks of anatase $\mathrm{TiO}_{2}$ were clearly observed. Figures 7-9 show the top view and side view of $\mathrm{TiO}_{2}$ nanotube arrays. The top views in Figures $7(\mathrm{a}), 8(\mathrm{a})$, and $9(\mathrm{a})$ show that all of the $\mathrm{TiO}_{2}$ nanotube arrays had the diameters between $100 \mathrm{~nm}$ and $140 \mathrm{~nm}$. The surfaces of $\mathrm{TiO}_{2}$ nanotube arrays with electrochemical polishing-chemical etching and chemical etching processes were smoother than that of $\mathrm{TiO}_{2}$ nanotube arrays with polishing-chemical etching process. The side views in Figures $7(\mathrm{~b}), 8(\mathrm{~b})$, and $9(\mathrm{~b})$ show that the lengths of $\mathrm{TiO}_{2}$ nanotube arrays with the polishing-chemical etching, electrochemical polishing-chemical etching, and chemical etching processes are $19.6 \mu \mathrm{m}, 18.2 \mu \mathrm{m}$, and $22.6 \mu \mathrm{m}$, respectively. From the side views in Figures 7-9 $\mathrm{TiO}_{2}$ nanotube arrays with the polishing-chemical etching process are not good as the photoelectrodes of DSSCs because $\mathrm{TiO}_{2}$ nanotube arrays are easily peeled off. Figures $8(\mathrm{~b})$ and $9(\mathrm{~b})$ show that the $\mathrm{TiO}_{2}$ nanotube arrays with polishing-chemical etching and chemical etching processes are not easily to be peeled off. Figure 7(b) also shows that the $\mathrm{TiO}_{2}$ nanotube arrays reveal an unsmooth surface, which will influence the transmission ratio and will be proven in Figure 10.

3.3. Transmission of Photoelectrodes Nanotubes. The transmission ratios of $\mathrm{TiO}_{2}$ nanotube arrays are shown in Figure 10 as a function of different polishing process and optical wavelength. The measured structure includes the layers of $\mathrm{TiO}_{2}$ nanotube arrays (photoelectrode), dye, electrolyte, and counter electrode. When the sunlight passes through the photoelectrode layer to dye layer, the transmission ratio has no apparent change. The results in Figure 10 show that the structures with the polishing-chemical etching (70-75\%) and electrochemical polishing-chemical etching processes (80-85\%) have high transmission ratio in the range of visible light. The structure with the polishing-chemical etching process has the lower transmission ratio which is caused by the being peeled off and unsmooth surfaces. Because $\mathrm{TiO}_{2}$ nanotube arrays with the chemical etching process have the thicker thickness, the transmission ratio (20-25\%) is very low. From those results, the electrochemical polishing-chemical etching and chemical etching processes are the better for formation of $\mathrm{TiO}_{2}$ nanotube arrays than polishing-chemical etching 


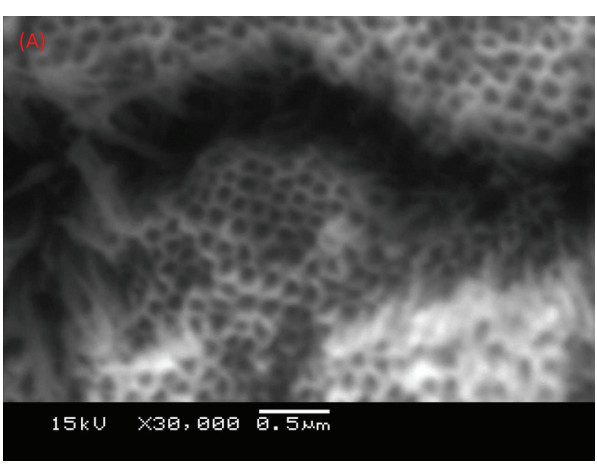

(a)

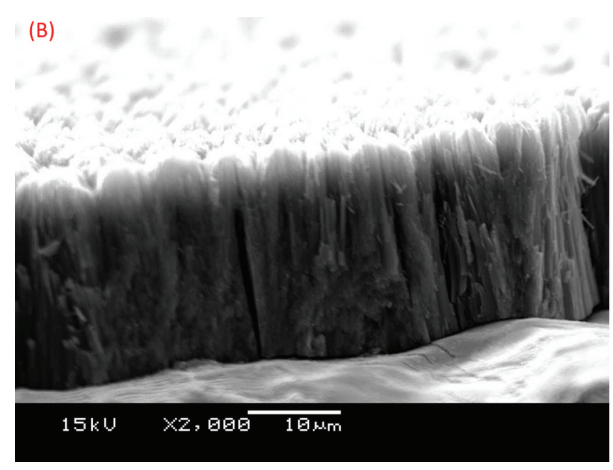

(b)

FIgure 9: Morphologies of the $\mathrm{TiO}_{2}$ nanotube arrays grown on chemical etching Ti plates (a) top view and (b) side view.

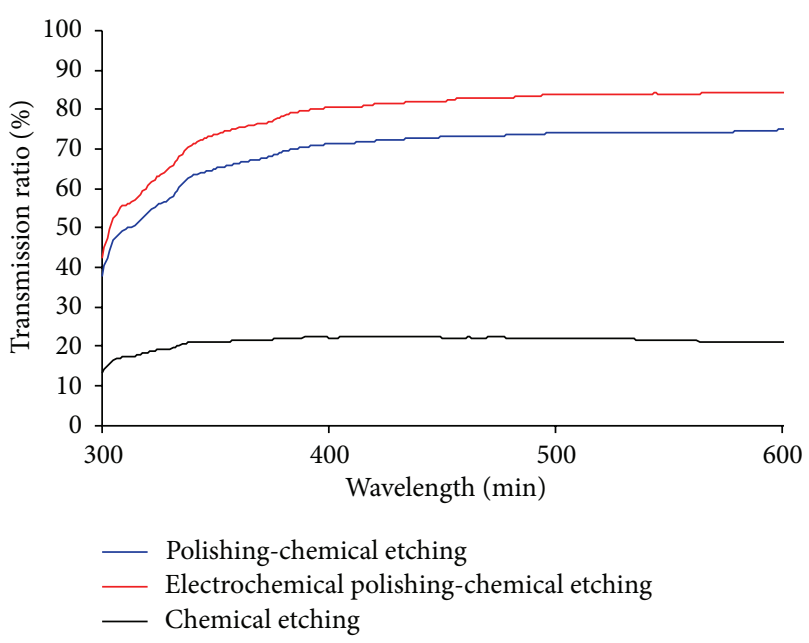

FIGURE 10: Transmission ratio curves of the $\mathrm{TiO}_{2}$ nanotube arrays grown on etching Ti plates.

process because they have the better structure and morphology factors to get the better characteristics of $\mathrm{TiO}_{2}$ nanotube arrays as the photoelectrodes of DSSCs.

\section{Conclusions}

In this study, three different methods were used to etch $\mathrm{Ti}$ template from 10 to $17 \mathrm{~min}$, the experimental results were summarized as follows.

(i) The thicknesses of the polishing-chemical etching, electrochemical polishing-chemical etching, and chemical etching Ti plates decreased from $75.3 \mu \mathrm{m}$ to $33 \mu \mathrm{m}$, from $60.4 \mu \mathrm{m}$ to $23.6 \mu \mathrm{m}$, and from $50 \mu \mathrm{m}$ to $14.8 \mu \mathrm{m}$, respectively.

(ii) The $\mathrm{TiO}_{2}$ nanotube arrays with polishing-chemical etching, electrochemical polishing-chemical etching, and chemical etching processes have the lengths of $19.6 \mu \mathrm{m}, 18.2 \mu \mathrm{m}$, and $22.6 \mu \mathrm{m}$, respectively, and their diameters were between $100 \mathrm{~nm}$ and $140 \mathrm{~nm}$.

(iii) In the range of visible light, the $\mathrm{TiO}_{2}$ nanotube arrays with polishing-chemical etching (70-75\%) and electrochemical polishing-chemical etching (80$85 \%)$ processes had the higher transmission ratio than that of the $\mathrm{TiO}_{2}$ nanotube arrays with chemical etching process (20-25\%).

(iv) The electrochemical polishing-chemical etching and chemical etching processes were better for formation of $\mathrm{TiO}_{2}$ nanotube arrays than the polishing-chemical etching process because they could fabricate $\mathrm{TiO}_{2}$ nanotube arrays with the better characteristics to be used as the photoelectrodes of DSSCs.

\section{Acknowledgments}

The authors acknowledge financial support from NSC 1012514-S-003-004-, NSC 101-3113-S-262-001-, and NSC 1012622-E-003-002-CC3.

\section{References}

[1] M. Paulose, K. Shankar, S. Yoriya et al., "Anodic growth of highly ordered $\mathrm{TiO}_{2}$ nanotube arrays to $134 \mu \mathrm{m}$ in length," The Journal of Physical Chemistry B, vol. 110, no. 33, pp. 16179-16184, 2006.

[2] M. Law, L. E. Greene, J. C. Johnson, R. Saykally, and P. D. Yang, "Nanowire dye-sensitized solar cells," Nature Materials, vol. 4, no. 6, pp. 455-459, 2005.

[3] G. K. Mor, K. Shankar, M. Paulose, O. K. Varghese, and C. A. Grimes, "Use of highly-ordered $\mathrm{TiO}_{2}$ nanotube arrays in dyesensitized solar cells," Nano Letters, vol. 6, no. 2, pp. 215-218, 2006.

[4] A. Fujishima and K. Honda, "Electrochemical photolysis of water at a semiconductor electrode," Nature, vol. 238, no. 5358, pp. 37-38, 1972.

[5] M. A. Gondal, M. N. Sayeed, and A. Alarfaj, "Activity comparison of $\mathrm{Fe}_{2} \mathrm{O}_{3}, \mathrm{NiO}, \mathrm{WO}_{3}, \mathrm{TiO}_{2}$ semiconductor catalysts in phenol degradation by laser enhanced photo-catalytic process," Chemical Physics Letters, vol. 445, no. 4-6, pp. 325-330, 2007.

[6] Y. Li, W. Xie, X. Hu et al., "Comparison of dye photodegradation and its coupling with light-to-electricity conversion over $\mathrm{TiO}_{2}$ and ZnO," Langmuir, vol. 26, no. 1, pp. 591-597, 2010.

[7] N. K. Allam and M. A. El-Sayed, "Photoelectrochemical water oxidation characteristics of anodically fabricated $\mathrm{TiO}_{2}$ nanotube arrays: structural and optical properties," Journal of Physical Chemistry C, vol. 114, pp. 12024-12029, 2010. 
[8] M. Gotic, M. Ivanda, A. Sekulic, S. Popovic, A. Turkovic, and K. Furic, "Microstructure of nanosized $\mathrm{TiO}_{2}$ obtained by sol-gel synthesis," Materials Letters, vol. 28, pp. 225-229, 1996.

[9] W. Li, S. I. Shah, C. P. Huang, O. Jung, and C. Ni, "Metallorganic chemical vapor deposition and characterization of $\mathrm{TiO}_{2}$ nanoparticles," Materials Science and Engineering B, vol. 96, no. 3, pp. 247-253, 2002.

[10] J. Choi, R. B. Wehrspohn, J. Lee, and U. Gösele, "Anodization of nanoimprinted titanium: a comparison with formation of porous alumina," Electrochimica Acta, vol. 49, no. 16, pp. 26452652, 2004.

[11] D. Gong, C. A. Grimes, O. K. Varghese et al., "Titanium oxide nanotube arrays prepared by anodic oxidation," Journal of Materials Research, vol. 16, no. 12, pp. 3331-3334, 2001.

[12] V. Zwilling, M. Aucouturier, and E. Darque-Ceretti, "Anodic oxidation of titanium and TA6V alloy in chromic media. An electrochemical approach," Electrochimica Acta, vol. 45, no. 6, pp. 921-929, 1999.

[13] R. Beranek, H. Hildebrand, and P. Schmuki, "Self-organized porous titanium oxide prepared in $\mathrm{H}_{2} \mathrm{SO}_{4} / \mathrm{HF}$ electrolytes," Electrochemical and Solid-State Letters, vol. 6, no. 3, pp. B12-B14, 2003.

[14] S. Sobieszczyk, "Self-organized nanotubular oxide layers on $\mathrm{Ti}$ and Ti alloys," Journal of Materials Science, vol. 9, no. 20, pp. 2541, 2009.

[15] K. M. Reddy, S. V. Manorama, and A. R. Reddy, "Bandgap studies on anatase titanium dioxide nanoparticles," Materials Chemistry and Physics, vol. 78, no. 1, pp. 239-245, 2003.

[16] J. I. Kim, S. Y. Lee, and J. C. Pyun, "Characterization of photocatalytic activity of $\mathrm{TiO}_{2}$ nanowire synthesized from Ti-plate by wet corrosion process," Current Applied Physics, vol. 9, no. 4, pp. e252-e255, 2009. 

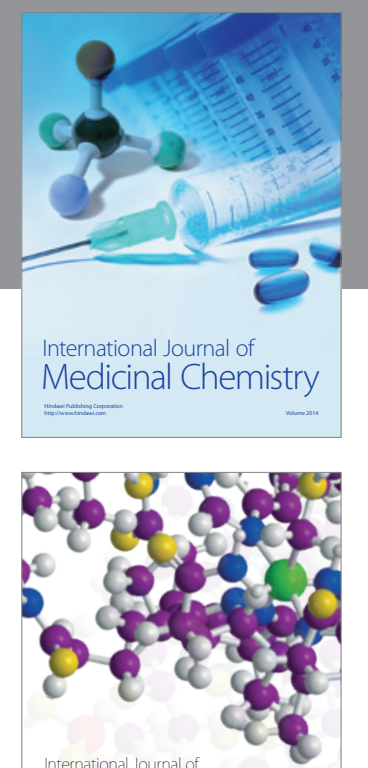

\section{Carbohydrate} Chemistry

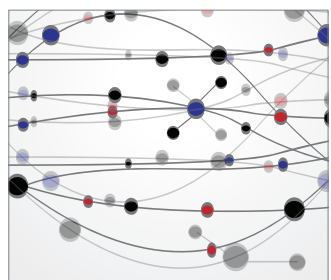

The Scientific World Journal
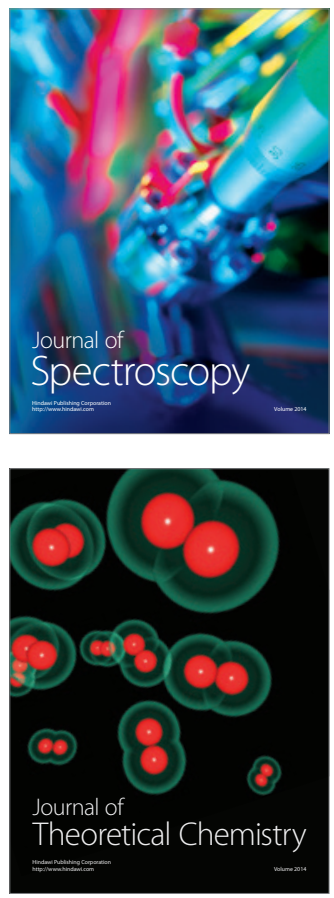
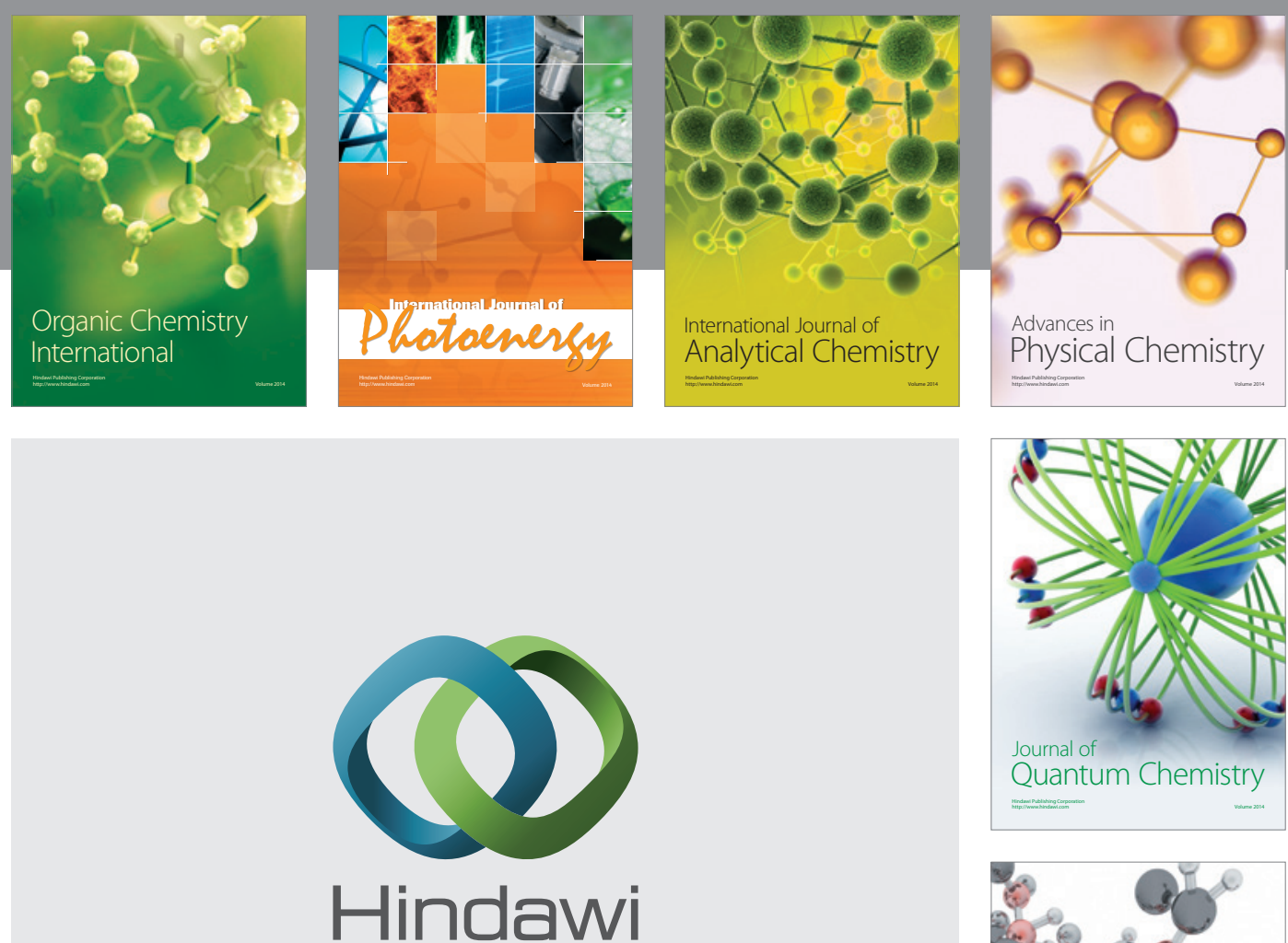

Submit your manuscripts at

http://www.hindawi.com

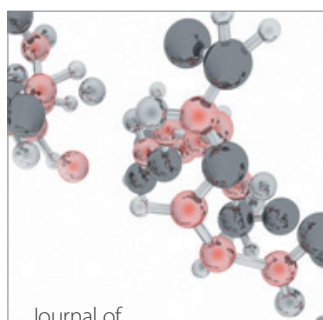

Analytical Methods

in Chemistry

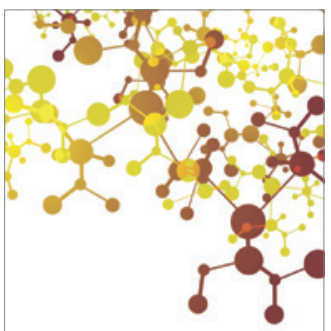

Journal of

Applied Chemistry

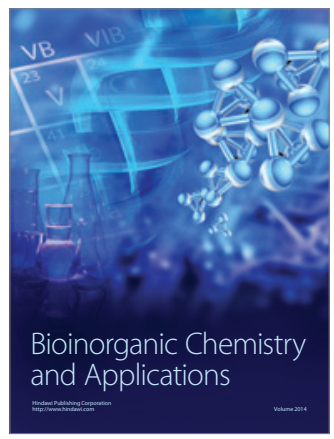

Inorganic Chemistry
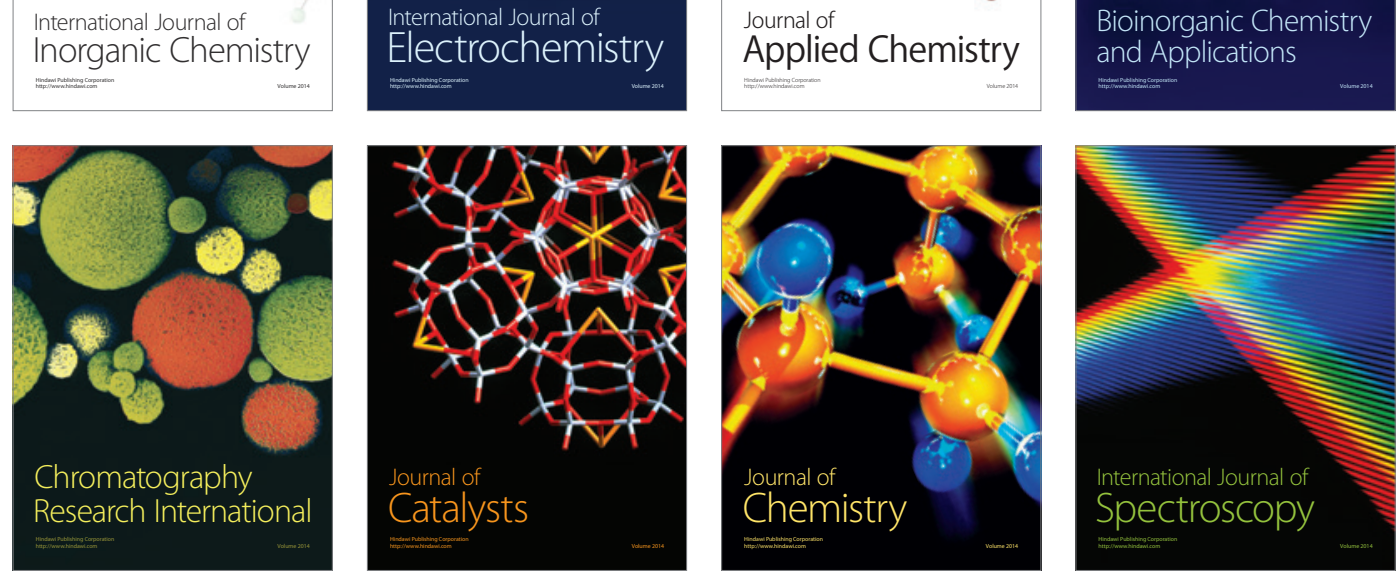